\title{
Deployment of Renewable Energies in Germany: Spatial Principles and their Practical Implications Based on a GIS-Tool
}

\author{
Stephan Bosch ${ }^{1}$ and Joachim Rathmann ${ }^{2}$ \\ ${ }^{1}$ Institute of Geography, University of Augsburg, Augsburg, 86159, Germany \\ ${ }^{2}$ Institute of Geography and Geology, University of Würzburg, Würzburg, 97074, Germany \\ Correspondence: Stephan Bosch (stephan.bosch@geo.uni-augsburg.de)
}

Received: 25 May 2018 - Revised: 31 July 2018 - Accepted: 3 August 2018 - Published: 9 August 2018

\begin{abstract}
GIS-based approaches for the optimal expansion of renewable energies are characterized by a strong dominance of engineering-oriented perspectives. It is acknowledged that combining techno-economic site analysis with social aspects can be beneficial for acceptance. However, this strategy's success is limited if essential theoretical perceptions obtained from social and economic sciences are neglected, degrading social parameters to simplified elements of GIS-based approaches. The study discusses the fundamental criticism of a techno-economic oriented and targetdeterministic energy planning by GIS. Proceeding from this, more complex approaches to the integration of social perspectives into GIS-planning tools are exemplified.
\end{abstract}

\section{Introduction}

Due to their low energy density, renewable energies are rather area intensive, therefore requiring close arrangements with different demands for space (e.g., nature protection, recreational areas, settlements). Geographic Information Systems (GIS) offer appropriate techniques for overcoming competing space demands in the context of renewable energies (Blaschke et al., 2013). From the beginning of the Energy Transition until today, GIS-related approaches have mainly been focused on an engineering point of view, neglecting social and environmental aspects (Upreti and Horst, 2004; Devine-Wright, 2005; Ellis et al., 2007; Zoellner et al., 2008; Aitken, 2010). This predominantly technology-based line of action may hamper social acceptance of renewable energies. Although GIS-tools increasingly integrate social aspects (see Sunak et al., 2015; Höfer et al., 2016), these are commonly based on simplified assumptions and cannot adequately re- flect the complex variety of ecological and social aspects that are important for the acceptance of renewable energies (Calvert et al., 2013). Therefore, the aim of the study is to focus on social aspects using GIS for site planning in renewable energies in order to examine how specific landscapes became identified as "acceptable locations" for specific renewable energy technologies. Essentially, the newly developed GIS planning tool aims to overcome the shortcomings of present ones by detaching from the technology-orientated perspective and focusing on the social and environmental suitability of sites for renewable energies (wind energy, biomass, photovoltaics, and geothermal energy), while also integrating spatial dynamics. The GIS-tool should have the potential to quickly change economic, ecological and social parameters in order to map and interpret the spatial dynamics of renewable energy site planning.

\section{State of Research}

Land use must always be regarded as a dynamic system that adapts to changing economic, ecological, and social boundary conditions (Lambin and Geist, 2006). Recent regional planning, however, sets minimum installation targets for windy locations (Einig and Zaspel-Heisters, 2015, 574 578), neglecting possible future changes in the ecological and social framework. Yet those changes might result in an advantage for technologies other than the presently preferred wind energy. Criticizing the unreflecting use of GIStools, Cowell (2010, 223-228) calls the prefixed wind energy sites "foreshadowed search areas" that omit both variable sociocultural implications and technological alternatives. Such tools often pretend to integrate several aspects to a holistic picture, while in fact focusing on a purely technological per- 
spective (Blaschke et al., 2013, p. 9). An entirely economic and technology specific approach offers the possibility of standardizing site potentials according to the energy density (measured in $\mathrm{W} \mathrm{m}^{-2}$ ) (Palmas et al., 2015, 10-14). In that regard, maps and statistics produced by GIS-tools appear as objective evidence, as the visual expression of power to fulfil administrative requirements in site planning. However, planning becomes feasible only if based on a collection of statistics obtained by generalizing social and ecological parameters (Murdoch, 2000). Previous GIS-based approaches - e.g., Quinonez-Varela et al. (2007), Tegou et al. (2010), Grassi et al. (2012), Omitaomu et al. (2012), Sunak et al. (2015), Höfer et al. (2016) - are generally user-friendly advisory instruments, but not appropriately complex for basic research projects dealing with social challenges in the energy transition. Several studies criticize the strong focus on the characteristics of a specific technology, i.e., its technological potential, that entirely disregards the negotiation processes in site planning of renewable energies (Zoellner et al., 2008; Palmas et al., 2015; Bosch et al., 2016). The gap between the technological potentials of renewable energies and the social implications of energy transitions hence cannot be bridged by conventional GIS-planning tools. Blaschke et al. (2013, p. 9) thoroughly describe the major challenges in integrating the human dimension into the energy landscape concept. Landscape includes the binding of people to places, symbols, power and the everyday experience of cultural landscapes. Taking these notions into account, a purely technological view on energy appears unduly simplified. Accordingly, public resistance often arises from landscape changes in favour of renewable energies (Pasqualetti, 2013). Integrating renewable energies into cultural landscapes without gravely harming scenic landscapes and obstructing the view on cultural heritages remains a challenging task. In sum, the complex process of site planning cannot be explained by simple GIS-based analyses, which however can well reproduce energy supply and demand. Sunak et al. (2015) and Höfer et al. (2016) try to overcome the shortcomings of previous planning tools by using a holistic multi-criteria decision making approach in order to specifically underline social acceptance. Yet the main results are limited to variable distances (e.g., from natural environments) and wind energy potential, both of which do not depict social variables such as participation and fairness.

\section{Methods}

In most European countries, spatial planning does not explicitly deal with "energy spaces" (Blaschke et al., 2013, 45 ) in the sense allocating a certain space to the production of energy without predefining the applied energy technology. However, a greater openness towards the whole scope of available energy technologies is urgently needed in order to be able to deal with the energy transition. The approach pre- sented here is guided by the hypothesis that in principle, each space is suitable for a specific renewable energy (Bosch et al., 2016). Yet as the capacity of hosting different renewable energy technologies is closely linked to geographical conditions and landscape perception by the inhabitants, regional site planning shows a widespread spatial variation (Warren and McFadyen, 2010; Bhowmik et al., 2017). Additionally, planning tools must take into account technological progress and the dynamics of economic competition (Tiba et al., 2010; Fripp, 2012). New technologies can lead to a better integration of renewable energies into sensible spaces and raise social acceptance. A major challenge is presented by different time-axes ranging from short term technological progress to long term regional planning processes. Moreover, space itself must be regarded differentiated. The dominant land use in a given area leads to the classification of subspaces according to their predominant function. These subspaces also differ from one another in terms of their demands on the development of renewable energies (Resch et al., 2014; Bosch et al., 2016). In the latter sense, the main criterion of classification is a space's vulnerability to mechanization. This concept is based on the idea that within different subspaces, different economic, ecological, and social targets exist, leading to a varying degree of robustness or sensitivity to technologic interference according to the predominant usage of space. For that reason, each subspace puts its own demand to the modus operandi of renewable energy deployment. E.g., while rather sensitive subspaces will have high demands on a technology's landscape integration and eco-sensitivity, in less sensitive subspaces, the focus will be on low production cost and high energy output. In consequence, the novel approach to the development of renewable energies is no longer determined by technological requirements based on economic considerations (e.g., average annual wind speed, biomass potential, and solar irradiance). Rather, the demands put to the various technologies as minimum social, ecologi$\mathrm{cal}$, and economic requirements by the subspaces are made the field of attention. The Bavarian planning region Augsburg served as an example for our study; in principle, any region or area for which basic information is available may be investigated. The specific subspaces were identified according to the predominant land use obtained from the CorineLand-Cover data. They were then newly classified with regard to the guidelines of German spatial planning. That way, it was possible to allocate any area to one of the following subspaces:

a. Sensitive Space: This type of space contains areas deserving special protection as it is very susceptible to any interaction. Sensitive Space is made up of Fauna-Flora-Habitat-Areas, SPA-OrnithologyPreservation-Areas, Nature Conservation Areas, Landscape Protection Areas, National Parks, and RamsarSites. 
b. Touristic Space: This type of space's main characteristics are important elements of cultural landscape, which are particularly relevant for its recreational function. It is made up of the following elements of cultural landscape: churches, chapels, monasteries, places of pilgrimage, synagogues, fortified hill tops, castle ruins, fortresses, castles, geosites, and natural memorials.

c. Agricultural Space: Farmlands and grasslands are summarized as Agricultural Space. The production of food and animal feedstuff is its key task. Likely, this type of space is ecologically jeopardized by intensive agricultural utilization (soil erosion, eutrophication etc.).

d. Silvicultural Space: This subspace contains the categories deciduous, coniferous, and mixed forests. In case a woodland belongs to a category of a higher protection level, then this space is not defined as Silvicultural Space, but as Sensitive Space, i.e., the more vulnerable category of space.

e. Burdened Space: This space has already been strongly altered by transport infrastructure, so that any further kind of alternation by renewable energies cannot lead to any further degradation. In this context, conversion areas are also classified as Burdened Space. According to the German Renewable Energy Act, this includes both military and civilian conversions.

The following nine parameters have been determined for the assignment of technological preconditions and specific requirements of the subspaces: Production costs, full load hour, controllability, spatial efficiency, licensing, landscape integration, eco-balance, participation, and renaturation capability. These are parameters that can easily be quantified (e.g., production costs $=\mathrm{ct} \mathrm{kWh}^{-1}$ ) illustrated using GIStools. The tool does however also contain parameters such as landscape integration, that are hard to grasp as they are subject to personal or constructivist interpretation - which in turn degrade the explanatory capacity of cartographic visualization. Still the attempt was made to likewise integrate these parameters in the presented analysis. E.g., technologic preconditions regarding the abstract factor Landscape Integration were deduced from an extensive review of the literature on the scenic impacts of various renewable energies. The operationalization of the factor Participation is instead based on the evaluation of structures of participation within any project hitherto initiated in the studied region, from which the participation potential of future projects can be derived. Both the demands of subspaces and the technologic preconditions can be chosen freely in the tool's input screen. After inserting the respective data, the tool offers the possibility of comparing the parameter values of specific technologies and specific subspaces. These values are calculated for every technology and every subspace. To every subspace, only the technology with the highest degree of accordance is assigned. Moreover, by changing the technological parameter, the spatial consequences of technological progress can be simulated. The user can easily vary the parameter values for the specific technologies and thus quickly calculate the optimal spatial allocation of renewable energies. Different scenarios (e.g., spatial implications of decreasing economic costs) based on different technological requirements can be visualized. The planning tool was developed using ArcPy site package. The ArcPy model has been published as Geoprocessing Service on one ArcGIS Server. The model was embedded into an $\mathrm{Ar}-$ cGIS API for Javascript interface. All data used for regionalization are based on freely accessible data, made available by OpenStreetMap, the European Environment Agency, the Bavarian Surveying Administration, the Bavarian Environment Administration, and the administrative district offices. These data have been processed by different tools in order to avoid errors in the topology (e.g., Erase-Tool).

\section{Results}

\subsection{Spatial Classification}

The present study illustrates the integration of economic, social, and ecological parameters into a GIS-based planningtool. The use of the planning tool is exemplified by the Bavarian planning region Augsburg (SE-Germany, Fig. 1). Water surfaces and built-up areas were excluded from our analysis. The remaining parts of the region were classified into the above mentioned five different subspaces, depending on their vulnerability to different technologies.

Figure 1 shows the spatial distribution of the respective types of space within the planning region Augsburg. The predominant features are Burdened Space, which forms a line through the region, and Touristic Space, which infiltrates the region in patches. It is noteworthy that the nature park "Westliche Wälder (i.e., Western Woods)" as a landscape protection area, was not allocated to Silvicultural, but to Sensitive Space. In the special case of two types of space overlapping, areas are allocated to the type of space that has a higher sensitivity to mechanization by renewable energies. This leads to a high degree of space-compatibility.

\subsection{Allocation of space and technology}

The renewable energies were assessed with regard to their technological ability to satisfy the specific demands of subspaces concerning the above mentioned parameters. In order to visualize and operationalize the relationship of technology and subspace, the subspaces and parameters were listed in the tool's attribute table. Any technology that might satisfy the demands of a subspace considering a certain parameter is entered into the corresponding column. E.g., concerning the parameter Spatial Efficiency, three technologies - PV plants, wind power plants, and geothermal plants - can fulfil Sensitive Space's demand of a very high spatial efficiency and are 


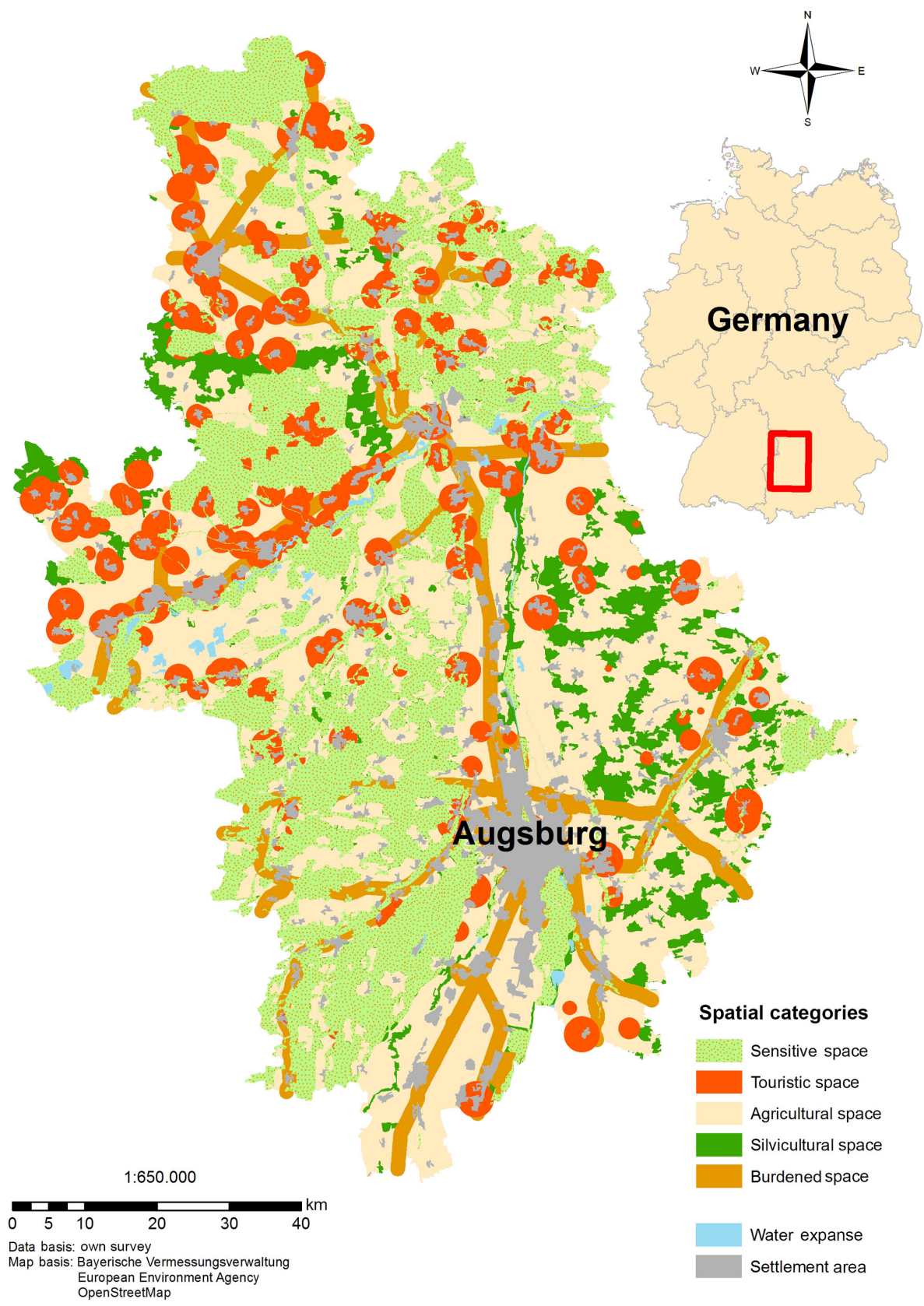

Figure 1. Subspaces of the planning region.

therefore enlisted in the respective column. That technology which in summary mostly satisfies the demand of space, is then allocated to the respective subspace as the most suitable solution (Fig. 2).

There is little sense in allocating a renewable energy to a subspace in which it may be spatially suitable, but not profitable. Therefore, a second step is taken in which from the layers of Fig. 2 those sites are extracted, in which the natural site factors actually allow a cost-effective operation of the most spatially compatible technology (Fig. 3). The study assumes a cost-effectiveness of wind power or solar power from an average annual wind speed of $5.5 \mathrm{~m} \mathrm{~s}^{-1}$ or a solar irradiance of more than $1150 \mathrm{kWh} \mathrm{m}^{-2}$ as well as a sunshine duration of more than $1650 \mathrm{~h} \mathrm{a}^{-1}$, respectively. Since the natural site factors concerning biogas and geothermal power enable a cost-effective operation in all of the area under investigation, the licensing requirements of the Federal Immission Control Act were used as a factor of differentiating subspaces.

Any change in the technological preconditions could lead to new site patterns for renewable energies. That is why site potentials of renewable energies and especially their opti- 


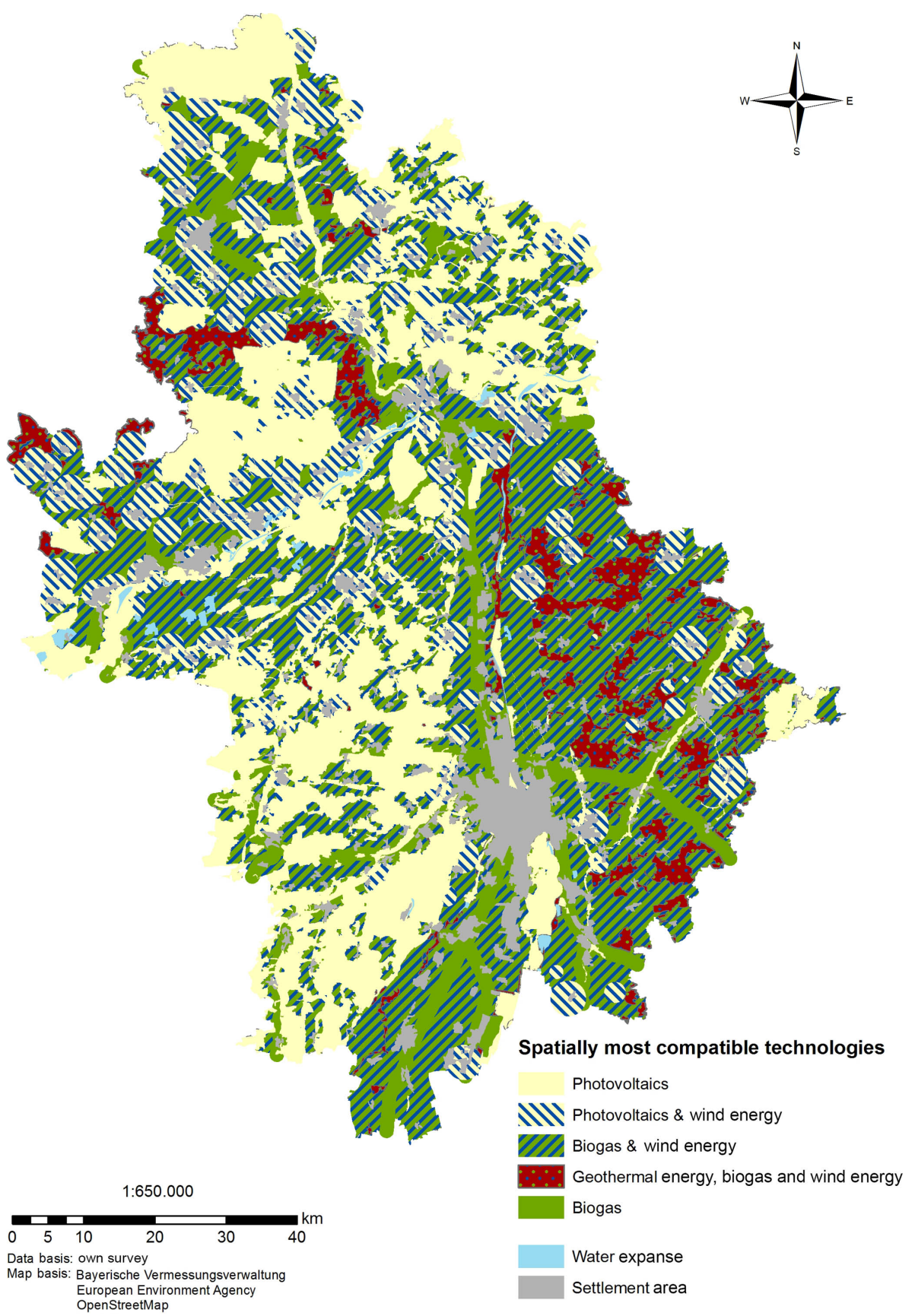

Figure 2. Spatially compatible assignment of technologies - current technological state.

mal spatial distribution need to be linked to prospective economic, social, environmental, and technological trends. A foresighted spatial planning tries to stake out corridors for evolving trends by means of scenarios, while trying to determine and interpret the sensitivity or resistibility of potential site patterns for renewable energies to economic, social, and technological changes, therefore also allowing for a better representation and understanding of mechanisms of competition among the different renewable energies. This implies that by including the factor time, renewable energies may access new subspaces and thereby become new rivals to other technologies. Accordingly, the robustness of a site pattern needs to be tested in scenarios by varying technological features.

In order to illustrate the spatial dynamics, it is assumed that by technological progress, the technology wind power will improve its performance regarding the parameters $\mathrm{Li}^{-}$ censing, Landscape Integration, and Participation by one cat- 


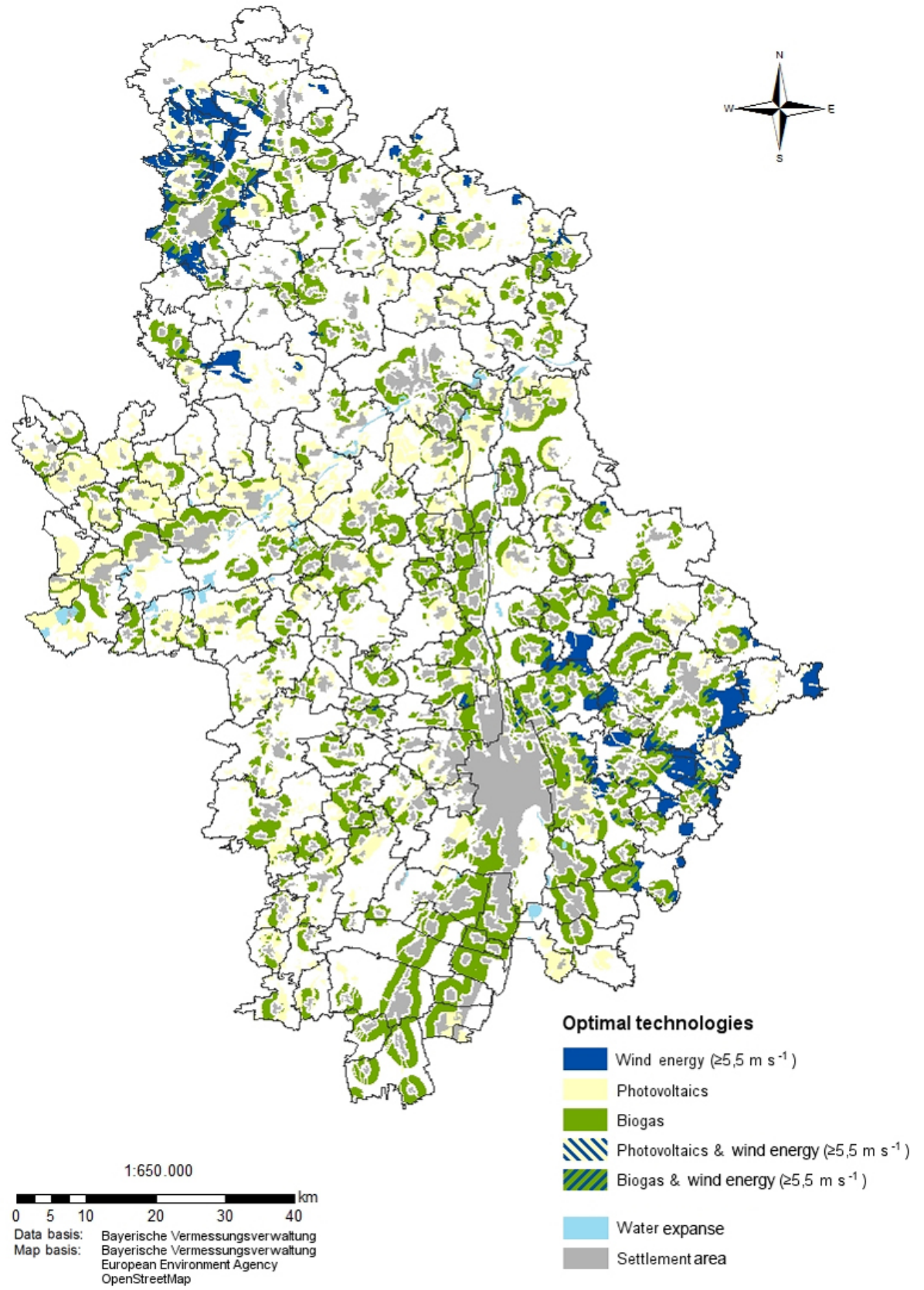

Figure 3. Spatially compatible assignment of technologies including optimal natural site factors - current technological state.

egory each. Variation of these three parameters leads to surprisingly great spatial dynamics: in large parts of the planning region, wind power advances to being the most spatially compatible technology, while ousting biogas and PV plants (compare Fig. 4 with Fig. 2). In Silvicultural and Burdened Space, in contrast, the established technologies are more robust to changes of technological frame conditions.

\section{Conclusions}

The present study visualizes for the first time the spatial dynamics of the expansion of renewable energies considering several technologies and site parameters including social aspects by use of a web-based GIS planning tool. The innovative planning tool differs from other ones as it equally considers wind energy, biomass, photovoltaics, and geothermal energy, hence enabling an open-ended site decision. Several parameters can be used to compare different sites in terms 


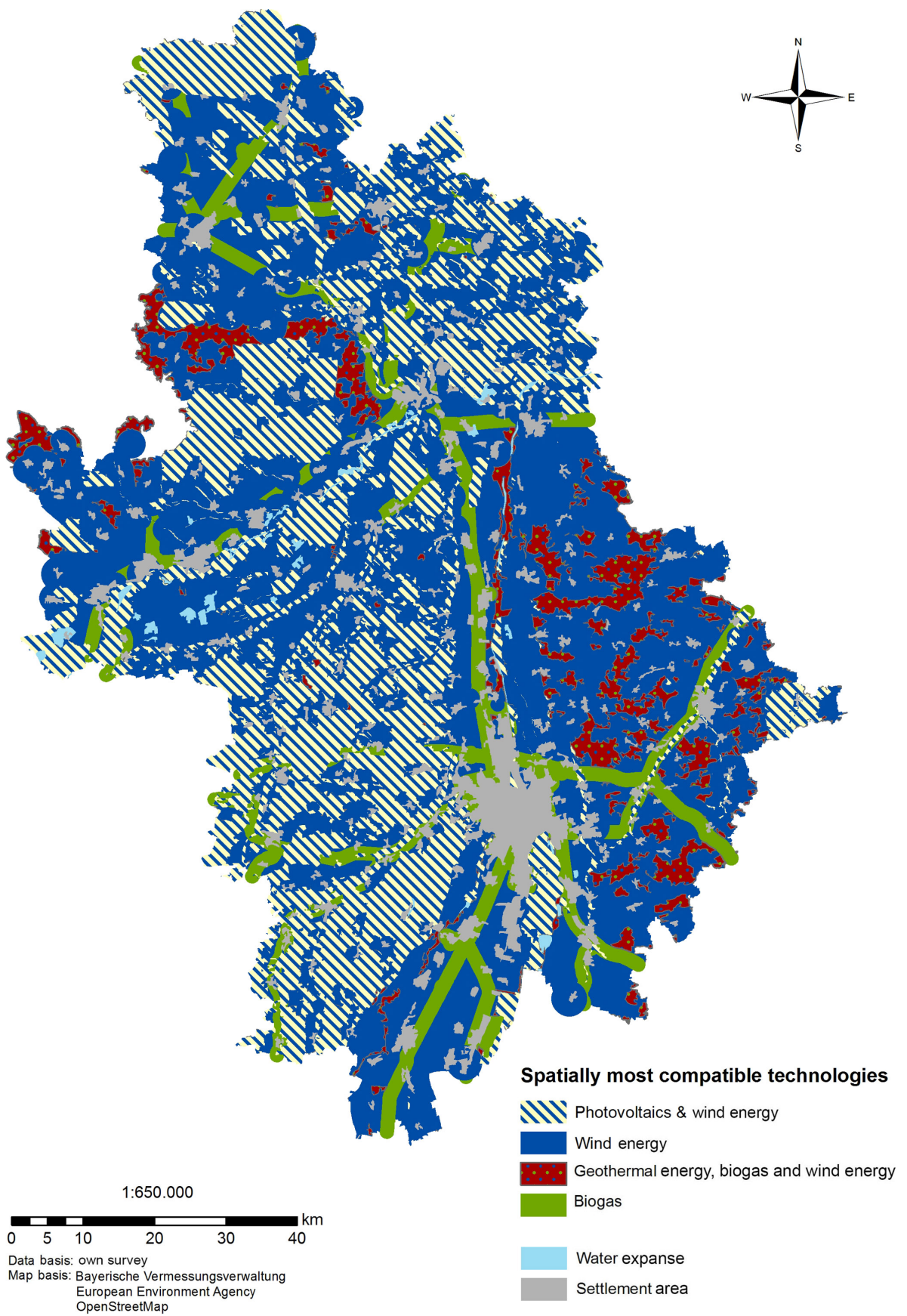

Figure 4. Spatially compatible assignment of technologies - scenario technological progress.

of suitability. Social (landscape integration, participation, licensing), ecological (spatial efficiency, renaturation capability, eco-balance), and economic parameters (production cost, controllability, full load hours) are integrated into the decision tool, which represents a novelty compared to previous GIS-tools. Some parameters, e.g., landscape aesthetics and participation, hardly can be quantified. For the operationalization of the latter, regional frequencies of the operational forms were collected in order to obtain probabilities of com- municative and financial participation. The essential innovation integrated into the GIS-tool is the potential to quickly change economic, ecological and social parameters; thus, maps of the spatial dynamics of renewable energy site planning can easily be calculated. The user interface consists of different input fields for technology prerequisites (e.g., production costs, spatial efficiency, participation), but also for the different classifications of subspaces and their preconditions. Changes in site patterns between time 0 and time 1 
can be visualized, showing the robustness of a specific renewable energy technology to changes in the economic, ecological or social boundary conditions. The displacement of one technology by another can be simulated based on "optimal" site conditions. The presented GIS-tool's contribution to a higher acceptance regarding the deployment of energy projects lies on the one hand in the provision of better transparency throughout the planning process. Project developers can explain future assignments of areas to renewable energies much more easily to afflicted citizens as it has been the case hitherto, since the tool cartographically visualizes the interaction of technologic parameters and spatial preconditions in a descriptive way that is comprehensible even for non-professionals. It is to be expected that this will improve the legitimization of planning decisions, as the proceeding must also be justified by ecological and social factors, both of which are included in the tool's calculation and visualization. On the other hand, the tool provides an incentive for optimizing a technology not only in economical, but also in social and ecological aspects, since this leads directly to an advantage in the competition with other technologies - which can be spatially simulated and visualized by changing the respective parameters. The tool's limitations manifest themselves in the arbitrarily extensible catalogues of technologic parameters and types of space, but also in the variability of class limits as well as in those parameters that are hard to define (e.g., landscape aesthetics). Its function as a mediator between opposing positions of planners and afflicted citizens, however, remains the tool's great value.

Future GIS-based approaches have to bridge the gap between economically profitable and socially accepted solutions. This, however, is a great challenge, as a socially suitable site will never be a spatial option so long as it is not profitable. Therefore, to make GIS-tools more relevant for regional planning processes, entrepreneurs, and public administrations, more detailed cost-benefit-calculations are needed. Based on these economically optimal solutions, social and ecological aspects can be added and weighted. Thereby it is possible to show deviations from the economically optimal site by integrating social and ecological parameters, while still remaining within the profit zone for the plant operator. Moreover, it seems important to accredit greater relevance to the integration of social distances instead of spatial distances into GIS-analyses. In contrast to site factors, social distances, e.g., participation, right to co-determination, access to information, etc., may be regarded as a measure of the energy transition's fairness. In the face of social distances and their implications for the planning, installation, and acceptance of energy technologies, spatial distances may easily lose significance. Analyses of the regional energy potential hence must face the sociocultural and socioeconomic subtleties of regional energy transitions.
Data availability. The datasets generated during the study are available at reasonable request sent to the corresponding author.

Author contributions. SB conceived and designed the study; furthermore, SB developed the GIS-Tool. SB and JR investigated the literature, wrote the paper and revised the manuscript. SB and JR read and approved the manuscript.

Competing interests. The authors declare that they have no conflict of interest.

Special issue statement. This article is part of the special issue "European Geosciences Union General Assembly 2018, EGU Division Energy, Resources \& Environment (ERE)". It is a result of the EGU General Assembly 2018, Vienna, Austria, 8-13 April 2018.

Acknowledgements. The authors are grateful for the financial support provided by the German Research Foundation (DFG).

Edited by: Christopher Juhlin

Reviewed by: two anonymous referees

\section{References}

Aitken, M.: Why we still don't understand the social aspects of wind power: A critique of key assumptions within the literature, Energ. Policy, 38, 1834-1841, https://doi.org/10.1016/j.enpol.2009.11.060, 2010.

Bhowmik, C., Bhowmik, S., Ray, A., and Pandey, K. M.: Optimal green energy planning for sustainable development: a review, Renew. Sust. Energ. Rev., 71, 796-813, https://doi.org/10.1016/j.rser.2016.12.105, 2017.

Blaschke, T., Biberacher, M., Gadocha, S., and Schardinger, I.: Energy landscapes: Meeting energy demands and human aspirations, Biomass. Bioenerg., 55, 3-16, https://doi.org/10.1016/j.biombioe.2012.11.022, 2013.

Bosch, S., Rathmann, J., and Simetsreiter, F.: Raumverträglicher Ausbau von erneuerbaren Energien - ein alternativer Standortplanungsansatz für eine nachhaltige Energiewende, Geogr. Helv., 71, 29-45, https://doi.org/10.5194/gh-71-29-2016, 2016.

Calvert, K., Pearce, J., and Mabee, W. E.: Toward renewable energy geo-information infrastructures: Applications of GIS and remote sensing that build institutional capacity, Renew. Sust. Energ. Rev., 18, 416-429, https://doi.org/10.1016/j.rser.2012.10.024, 2013.

Cowell, R.: Wind power, landscape and strategic, spatial planning - The construction of "acceptable locations" in Wales, Land Use Policy, 27, 222-232, https://doi.org/10.1016/j.landusepol.2009.01.006, 2010.

Devine-Wright, P.: Beyond NIMBYism: towards and integrated framework for understanding public perceptions of wind energy, Wind Energy, 8, 125-139, https://doi.org/10.1002/we.124, 2005. 
Einig, K. and Zaspel-Heisters, B.: Eine Bilanz der Steuerung der Windenergienutzung durch die Raumordnung nach Fukushima, in: Informationen zur Raumentwicklung, Bundesinstitut für Bau-, Stadt- und Raumforschung, Bonn, 6, 571-589, 2015.

Ellis, G., Barry, J., and Robinson, C.: Many ways to say "no", different ways to say "yes": applying Qmethodology to understand public acceptance of wind farm proposals, J. Environ. Plann. Man., 50, 517-551, https://doi.org/10.1080/09640560701402075, 2007.

Fripp, M.: Switch: A planning tool for power systems with large shares of intermittent renewable energy, Environ. Sci. Technol., 46, 6371-6378, https://doi.org/doi:10.1021/es204645c, 2012.

Grassi, S., Chokani, N., and Abhari, R. S.: Large scale technical and economical assessment of wind energy potential with a GIS tool: Case study Iowa, Energ. Policy, 45, 73-85, https://doi.org/10.1016/j.enpol.2012.01.061, 2012.

Höfer, T., Sunak, Y., Siddique, H., and Madlener, R.: Wind farm siting using a spatial analytic hierarchy process approach: A case study of the Städteregion Aachen, Appl. Energ., 163, 222-243, https://doi.org/10.1016/j.apenergy.2015.10.138, 2016.

Lambin, E. F. and Geist, H. J. (Eds.): Land-use and land-cover change: Local processes and global impacts, Global Change The IGBP Series, Springer, Berlin, Heidelberg, New York, 2006.

Murdoch, J.: Space against time: competing rationalities in planning for housing, T. I. Brit. Geogr., 25, 503-519, 2000.

Omitaomu, O. A., Blevins, B. R., Jochem, W. C., Mays, G. T., Belles, R., Hadley, S. W., Harrison, T. J., Bhaduri, B. L., Neish, B. S., and Rose, A. N.: Adapting a GISbased multicriteria decision analysis approach for evaluating new power generating sites, Appl. Energ., 96, 292-301, https://doi.org/10.1016/j.apenergy.2011.11.087, 2012.

Palmas, C., Siewert, A., and von Haaren, C.: Exploring the decision-space for renewable energy generation to enhance spatial efficiency, Environ. Impact Assess., 52, 9-17, https://doi.org/10.1016/j.eiar.2014.06.005, 2015.

Pasqualetti, M. J.: Opposing wind energy landscapes: A search for common cause, in: The new Geographies of Energy. Assessment and Analysis of Critical Landscapes, edited by: Zimmerer, K., Routledge, New York, 206-216, https://doi.org/10.1080/00045608.2011.568879, 2013.
Quinonez-Varela, G., Cruden, A., Graham, C., Punton, B., Blair, L., and Thomson, J.: A GIS/PSS planning tool for the initial grid connection assessment of renewable generation, Renew. Energ., 32, 727-737, https://doi.org/10.1016/j.renene.2006.03.011, 2007.

Resch, B., Sagl, G., Törnros, T., Bachmaier, A., Eggers, J.-B., Herkel, S., Narmsara, S., and Gündra, H.: GIS-based planning and modeling for renewable energy: Challenges and future research avenues, ISPRS Int. Geo-Inf., 3, 662-692, https://doi.org/10.3390/ijgi3020662, 2014.

Sunak, Y., Höfer, T., Siddique, H., Madlener, R., and De Doncker, R. W.: A GIS-based decision support system for the optimal siting of wind farm projects, E.ON Energy Research Center Series, 7, 1-64, 2015.

Tegou, L. I., Polatidis, H., and Haralambopoulos, D. A.: Environmental management framework for wind farm siting: methodology and case study, Environ. Manage., 91, 2134-2147, https://doi.org/10.1016/j.jenvman.2010.05.010, 2010.

Tiba, C., Candeias, A. L. B., Fraidenraich, N., Barbosa, E. M. de S., de Carvalho Neto, P. B., and de Melo Filho, J. B.: A GIS-based decision support tool for renewable energy management and planning in semi-arid rural environments of northeast of Brazil, Renew. Energ., 35, 2921-2932, https://doi.org/10.1016/j.renene.2010.05.009, 2010.

Upreti, B. R. and van der Horst, D.: National renewable energy policy and local opposition in the UK: the failed development of a biomass electricity plant, Biomass. Bioenerg., 26, 61-69, https://doi.org/10.1016/S0961-9534(03)00099-0, 2004.

Warren, C. R. and McFadyen, M.: Does community ownership affect public attitudes to wind energy? A case study from South-West Scotland, Land Use Policy, 27, 204-213, https://doi.org/10.1016/j.landusepol.2008.12.010, 2010.

Zoellner, J., Schweizer-Ries, P., and Wemheuer, C.: Public acceptance of renewable energies: Results from case studies in Germany, Energ. Policy, 36, 4136-4141, https://doi.org/10.1016/j.enpol.2008.06.026, 2008. 